08

\title{
Особенности формирования и структуры ленгмюровских пленок титаната бария
}

\author{
(C) А.П. Кузьменко, И.В. Чухаева, П.В. Абакумов \\ Юго-Западный государственный университет, \\ 305040 Курск, Россия \\ ฯ e-mail: AbakumovPavel18@gmail.com
}

Поступило в Редакцию 3 августа 2018 г.

В окончательной редакции 3 августа 2018 г.

Принято к публикации 11 марта 2019 г.

Методом Ленгмюра-Блоджетт на установке KSV NIMA 2002 получены сегнетоэлектрические пленки стабилизированных наночастиц титаната бария из коллоидной системы водного раствора олеата натрия, обнаружены коагулянты с наиболее характерным гидродинамическим диаметром $~ 200 \mathrm{~nm}$, и предложена физическая модель их образования из наночастиц титаната бария в данной коллоидной системе. Осаждены однородные сегнетоэлектрические пленки с размером частиц титаната бария $\sim 20 \mathrm{~nm}$ и шириной запрещенной зоны $3.6 \mathrm{eV}$. Методами сканирующей зондовой и электронной микроскопии, колебательной и рентгенофотоэлектронной спектроскопии, а также рентгеновской дифрактометрии изучены топологические, структурные особенности и распределение химических элементов в полученных пленках на разных подложках.

Ключевые слова: титанат бария, пленки Ленгмюра, коагуляционный механизм, кристаллическая структура, ширина запрещенной зоны.

DOI: $10.21883 /$ JTF.2019.08.47898.2454

\section{Введение}

Сегнетоэлектрики с наноразмерной структурой, сочетая в себе уникальные свойства, привлекают большое внимание исследователей. Однако для их практического применения необходимо выполнить высокие требования по чистоте и бездефектности, которые достигаются выбором технологий получения.

Пленочные структуры из титаната бария (ВТО) уже нашли достаточно широкое практическое применение. В частности, пленки из $\mathrm{BaTiO}_{3}$ применяются в конденсаторах повышенной емкости [1], электрически управляемых сверхвысокочастотных (СВЧ) устройствах [2,3], элементах памяти [4].

Пленки титаната бария, получаемые различными методами, отличаются по структуре и, как следствие, по свойствам. Так, пленки ВТО, полученные методом осаждения из газообразной фазы (MOCVD) на Pt/MgO-подложках при температуре $873 \mathrm{~K}$, обладали гранулярной структурой произвольной ориентации, которая при температуре $973 \mathrm{~K}$ становилась столбчатой вдоль оси [001]. При этом отмечен рост как диэлектрической проницаемости, так и размера зерен [5]. В золь-гель пленках ВТО на кремниевых подложках после отжига $(873 \mathrm{~K})$ отмечался рост степени кристалличности [6]. Допированные $\mathrm{Nb}(1 \% \mathrm{amu})$ пленки $\mathrm{BTO} / \mathrm{SrRuO}_{3}$ толщиной $150 \mathrm{~nm}$ на горячей подложке $(873 \mathrm{~K})$, полученные методом импульсного лазерного осаждения [7], показали наилучшие управляемые поляризацию и переключение. Напыленные методом пиролиза аэрозоля пленки ВТО по данным структурных исследований имели значительную неодно- родность распределения кубической фазы по подложке, что понижало их сегнетоэлектрические свойства [8]. Наиболее качественная пленочная структура получена методом химического осаждения из плотноупакованных кристаллических зерен ВТО на кремниевой подложке с буферным слоем оксинитрата лантана [9]. Отметим, что во всех описанных случаях [5-9] для нанесения сегнетоэлектрических пленок требовались технически сложные условия.

Задачами настоящей работы являлись изучение коллоидной системы стабилизированных олеатом натрия наночастиц титаната бария, используемой для осаждения сегнетоэлектрических пленок методом Ленгмюра-Блоджетт, изучение влияния материала подложки на качество формирования покрытия, определение параметров кристаллической решетки и ширины запрещенной зоны получаемых в работе структур.

\section{Эксперимент}

Пленки из коллоидной системы (КС) стабилизированных наночастиц титаната бария в водном растворе олеата натрия - ST BTO/ $\mathrm{H}_{2} \mathrm{O}$ (концентрация $n=5 \cdot 10^{11} \mathrm{ml}^{-1}$, вязкость $\eta=1.528 \mathrm{cP}$, дисперсность $D=5 \cdot 10^{6} \mathrm{~m}^{-1}, \mathrm{pH} 7.56$, дзета потенциал $\xi=-68 \mathrm{mV}$ ) осаждались методом Ленгмюра-Блоджетт на установке KSV NIMA 2002, позволяющей как формировать пленки в термостабилизированном режиме (термостат JULABO F12-ED, $-20-+100^{\circ} \mathrm{C}$ с точностью $0.03^{\circ} \mathrm{C}$ ), так и контролировать этот процесс с помощью микро- 
скопа Брюстера-MicroBAM (разрешение $12 \mu \mathrm{m}$ ), сенсора поверхностного потенциала SPOT (чувствительность на рабочей частоте $300 \mathrm{~Hz}, 1 \mathrm{mV}$ ).

Коллоидная система ST BTO $/ \mathrm{H}_{2} \mathrm{O}$ исследована на анализаторе размера коллоидных частиц серии Malvern ZetaSizer Nano (лазер с длинной волны $\lambda=633 \mathrm{~nm}$ и мощностью $P=10 \mathrm{~mW}, 90^{\circ}$ и $173^{\circ}$ датчики, модель Эйнштейна-Стокса).

Топология полученных покрытий исследована на сканирующем зондовом микроскопе (C3M) AIST-NT SmartSPM. Толщина пленок ST BTO, элементный состав, кристаллическая и зонная структуры определены на сканирующем электронном микроскопе (СЭМ) - FEI Nova NanoSEM и просвечивающем электронном микроскопе (ПЭМ) Zeiss Libra-120. Химическая структура покрытий изучена методами колебательной спектроскопии: ИК спектрометр Инфраспек ФСМ-1201 (спектральное разрешение $1 \mathrm{~cm}^{-1}$ ) и рамановский микроспектрометр AIST-NT OmegaScope $(\lambda=532 \mathrm{~nm}, P=50 \mathrm{~mW}$, спектральное разрешение $3 \mathrm{~cm}^{-1}$, пространственное разрешение $0.5 \mu \mathrm{m})$, а также методом рентгеновской фотоэлектронной спектроскопии (РФЭС) - SPECS, PHOIBOS-150 (AlK $K_{\alpha}(1486.6 \mathrm{eV})$ и $\left.\operatorname{Mg} K_{\alpha}(1253.6 \mathrm{eV})\right)$. Кристаллическая структура и фазовый состав пленок ВTO изучены на дифрактометре - GBC EMMA $\left(\mathrm{Cu} K_{\alpha}\right.$, схема Брегга-Брентано, шаг $0.02^{\circ}$ ).

\section{Результаты и обсуждение}

Из химически чистых (reagent) реактивов были получены наночастицы ВТО в тетрагональной и кубической фазах с формой близкой к сферической методом пероксидного синтеза [10-12]. Стабилизация наночастиц достигалась обогащением их поверхности гидроксильными группами $-\mathrm{OH}^{-}$путем кипячения $(423 \mathrm{~K})$ в $30 \%$ раствоpe $\mathrm{H}_{2} \mathrm{O}_{2}$ в течение $3 \mathrm{~h}$. Полученные гидроксилированные наночастицы дополнительно модифицировались молекулами олеата натрия $\mathrm{C}_{17} \mathrm{H}_{33} \mathrm{COONa}$ (с гидрофобной $\left(\mathrm{C}_{17} \mathrm{H}_{33}\right)$ и гидрофильной $(\mathrm{COONa})$ частями) в процессе интенсивного перемешивания при температуре $358 \mathrm{~K}$ в течение $4 \mathrm{~h}$ в $0.5 \%$ водном растворе согласно $[11,12]$. Гомогенность коллоидных систем ВТО, используемых при осаждении пленки Ленгмюра-Блоджетт (ЛБ), повышалась в центрифуге MiniSpin plus, Eppendorf c ускорением $14000 g$.

Согласно данным малоуглового рентгеновского рассеяния (МУРР) [13], средние радиусы наночастиц в коллоидной системе ST BTO $/ \mathrm{H}_{2} \mathrm{O}$ составляли $5,12,27$ и $37 \mathrm{~nm}$. Однако ввиду низкой электронной плотности олеата натрия и его слабой упорядоченности по сравнению с кристаллическим ядром стабилизированной наночастицы, полученные данные МУРР соответствуют исключительно ядрам ВТО.

Более полная информация о размерах ST ВТО в КС с учетом наличия у них как ядра, так и оболочки, а также влияния на их размеры температуры была получена методом динамического рассеяния света (DLS) по аналогии с [14]. Распределения гидродинамических диаметров ST ВTO в КС при 298 К, а также при нагреве до $353 \mathrm{~K}$ и последующем остывании представлены на рис. $1, a$. Здесь же на вставке приведены гидродинамические диаметры исследуемых частиц ST ВТО в КС: $d_{\min }$ и $d_{\max }$, соответствующие их минимальным и максимальным значениям, а также $d-$ наиболее характерный диаметр в этом распределении.

Следует отметить, что если $d$ не сильно зависел от температуры, изменяясь от 200 до $220 \mathrm{~nm}$, т.е. в пределах погрешности измерений, то значения $d_{\min }$ и $d_{\max }$ как до нагревания, так и после остывания КС оставались неизменными - были обратимыми.

Наблюдаемое различие измеренных методом DLS гидродинамических размеров частиц в КС (рис. $1, a)$ и их средних радиусов (без центрифугирования) в этой же системе по данным МУРР [13] без видимых изменений его мутности может свидетельствовать о возможности их скрытой коагуляции. Из частиц каждого размера возникали агрегаты, которые, в свою очередь, выступали в качестве исходных частиц для последующей коагуляции в агломераты в соответствии с механизмом роста, предложенным в [15].

Применительно к исследуемой КС процесс коагуляции существенно возрастал при нагревании, о чем свидетельствовало увеличение доли агрегатов вблизи гидродинамического диаметра $200 \mathrm{~nm}$ при 353 К. Распределение размеров частиц в КС явно изменяет характер зависимости от логнормальной (при нормальных условиях) к нормальной при нагревании (рис. $1, a$ ). Схематично процесс объединения в агрегаты наночастиц ВТО в водном растворе олеата натрия продемонстрирован на рис. $1, b$.

На вставке к рис. $1, b$ представлены спектры рамановского рассеяния света водного раствора $\mathrm{NaC}_{18} \mathrm{H}_{33} \mathrm{O}_{2}$, в котором выделена линия $1646 \mathrm{~cm}^{-1}$, соответствующая углерод-углеродной связи $(\mathrm{C}=\mathrm{C})$, по энергии отвечающая ковалентному взаимодействию [16]. Здесь же приведен спектр для ST ВTO в этом растворе, на котором указанная линия отсутствует. Это говорит о структурном изменении в головной группе сорбированного на ВТО олеата натрия, что объясняет как образование, так и рост размеров агрегатов в соответствие со сценарием, приведенным на рис. $1, b$.

Также для объяснения процессов формирования коагулянтов ST ВТО в КС, очевидно, следует учесть химический состав компонентов, включающий положительные ионы Ti с зарядом до $4, \mathrm{Ba}-2$ и $\mathrm{Na}-1$. Способность таких комплексов к коагуляции может быть обусловлена положением Ti, Ва и Na в лиотропном ряду по закону шестой степени Дерягина-Ландау (правило Шульца-Гарди) $\left(1 / 1^{6}: 1 / 2^{6}: 1 / 4^{6}\right)$.

С учетом температуры синтеза наночастиц (363 K) расстояние между отдельными наночастицами ВТО $h$ должно возрастать за счет теплового движения. Будем исходить из теории Дерягина-Ландау-Фервея-Овербека, 


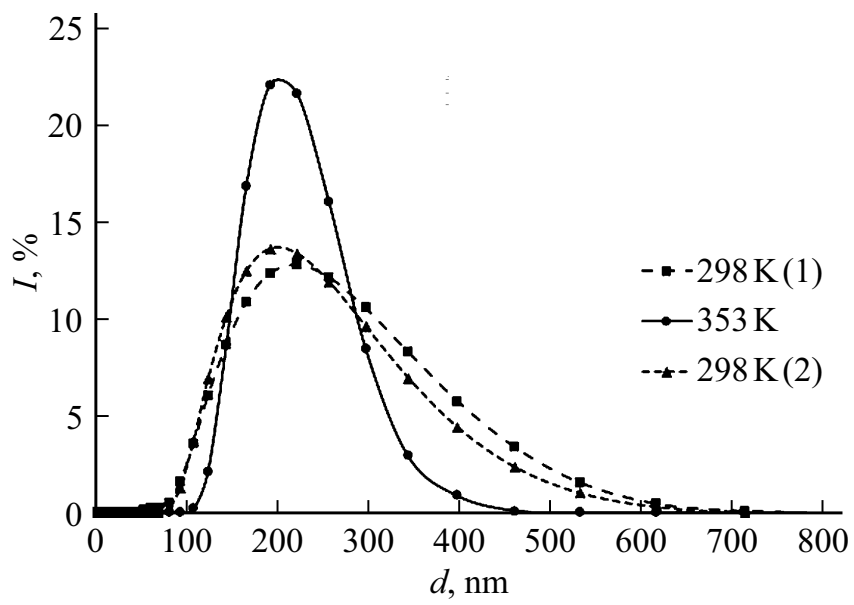

$a$

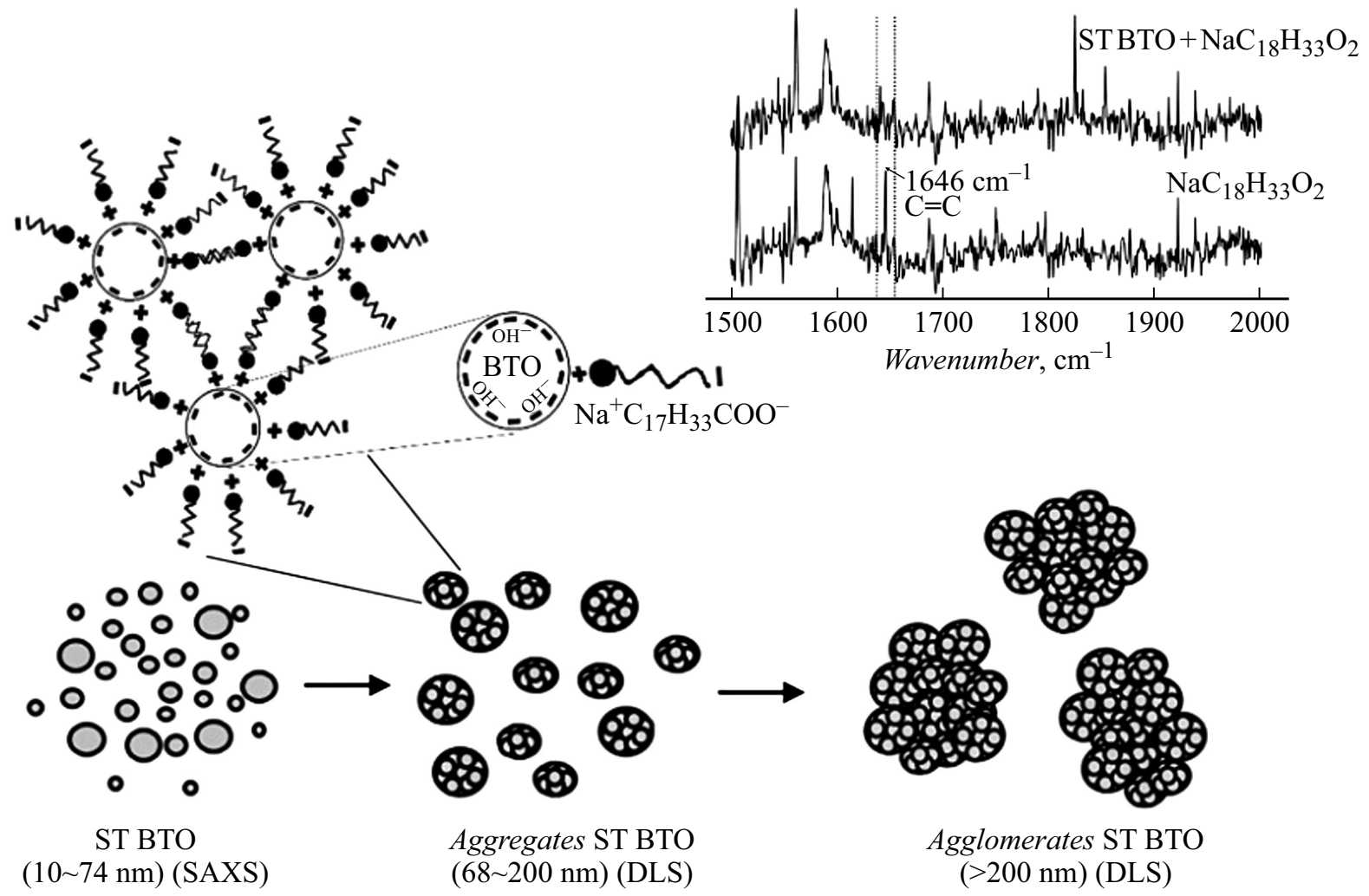

Рис. 1. $a$ - распределение по гидродинамическим размерам комплексов ST ВТО в КС при температурах 298 и $353 \mathrm{~K}, b-$ схема образования частица-агрегат-агломерат и раман спектры водного раствора олеата натрия и КС ST ВТО (на вставке).

в которой базовым является расклинивающее давление: $\Pi=f(h)$. Величина П определяется конкурентным вкладом сил отталкивания (электростатической природы $\left.U_{e}=A \exp (-a h)\right)$, и притяжения (Ван-дер-Ваальса) $A_{12} /\left(12 \pi h^{2}\right)$ :

$$
\left.U=U_{e}+U_{m}=A \exp (-a h)\right)+A_{12} /\left(12 \pi h^{2}\right) .
$$

Здесь $A, a-$ многофакторные величины, учитывающие составляющие компонентывзаимодействия, а $A_{12}$ константа Гамакера. Полная энергия взаимодействия в соответствии с (1) имеет два минимума. При этом если первый из них возникает на минимальных расстояниях

\begin{tabular}{|l|c|c|c|}
\hline $\mathrm{T}, \mathrm{K}$ & $d_{\text {min }}, \mathrm{nm}$ & $d_{\max }, \mathrm{nm}$ & $d, \mathrm{~nm}$ \\
\hline $298(1)$ & 68 & 650 & $220 / 12.8$ \\
\hline 353 & 106 & 459 & $200 / 22$ \\
\hline $298(2)$ & 68 & 650 & $200 / 13.4$ \\
\hline
\end{tabular}

$b$ 


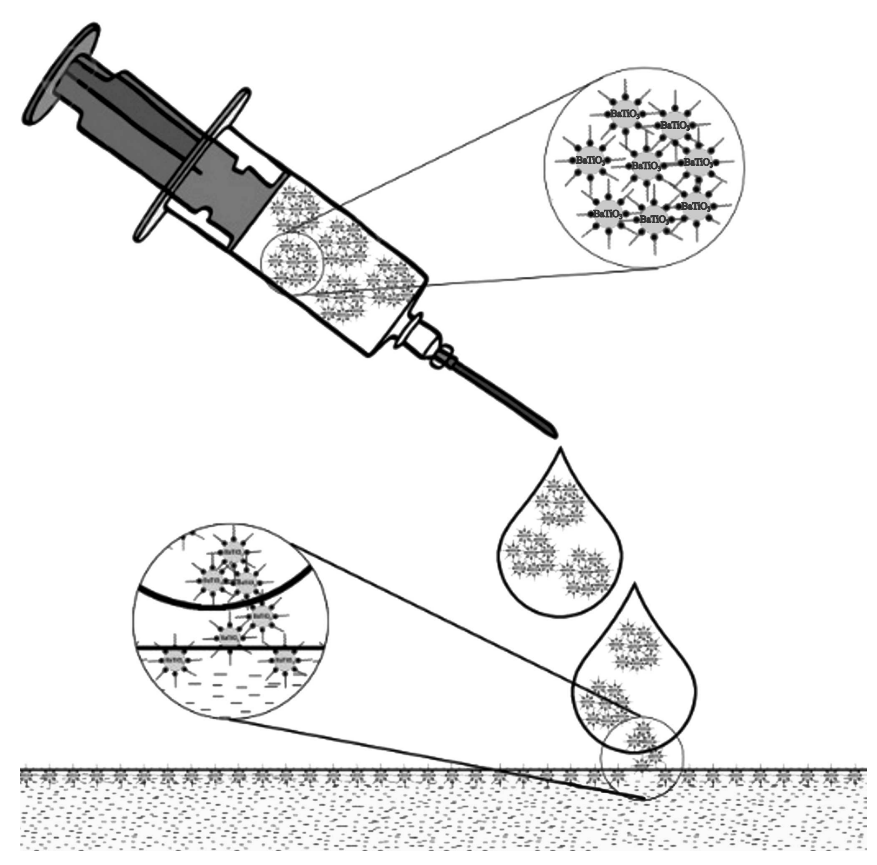

Рис. 2. Модель образования пленки ВТО на поверхности воды из коагулянтов.

Таблица 1. Топологические размеры поверхности подложки до и после осаждения пленки ВТО

\begin{tabular}{l|c|c|c}
\hline \multirow{2}{*}{ Тип подложки } & \multicolumn{2}{|c|}{$\begin{array}{c}\text { Средние размеры } \\
\text { структур, nm }\end{array}$} & $\begin{array}{c}\text { RMS шерохова- } \\
\text { тость, nm } \\
R_{\mathrm{S}} / R_{\mathrm{LB}}\end{array}$ \\
\cline { 1 - 3 } & подложка & пленка & \\
\hline Платина / Стекло & 6.8 & 20.6 & $9.15 / 3.92$ \\
Никель/Стекло & 6 & 8 & $0.9 / 0.93$ \\
Стекло & 6.4 & 6.4 & $1.29 / 1.36$ \\
Кремний & 6.8 & 22 & $0.38 / 2.91$ \\
Подложка & 7.4 & 22.2 & $0.99 / 2.02$
\end{tabular}

на диффузного слоя $-\lambda_{\mathrm{DL}}$. Максимальная величина $\lambda_{\mathrm{DL}}$ в соответствии с выводами из теории Дебая-Гюккеля определяется

$$
\lambda_{\mathrm{DL}}=\left(\varepsilon \varepsilon_{0} R T / 2 F^{2} I\right)^{1 / 2} .
$$

Здесь $\varepsilon_{0}-$ диэлектрическая постоянная, $R-$ универсальная газовая постоянная, $F-$ число Фарадея, $\varepsilon, I-$ диэлектрическая проницаемость дисперсионной среды и ионная сила раствора, зависящая только от его концентрации и заряда ионов $I=\sum C_{i} z_{i}$, не изменяются при нагревании. Согласно (2), $\lambda_{\mathrm{DL}}$ возрастает как $T^{1 / 2}$.

Уменьшение $d_{\max }$ в распределении по гидродинамическим размерам коагулянтов ST ВТО с большими размерами при нагревании можно объяснить более существенным тепловым расширением входящей в коагулянт $\mathrm{H}_{2} \mathrm{O}$ по сравнению с ее же расширением в коагулянтах с $d_{\min }$. В этих условиях величина углерод-углеродной связи в первом случае снижается, что может приводить к их распаду на более мелкие коагулянты.

В соответствии с выводами термодинамической теории агрегативной устойчивости [17] как наличие двойного электрического слоя (ДЭС), так и коагуляция наночастиц ВТО в КС за счет самоорганизации должны приводить к снижению поверхностной энергии, что следует из уравнения потенциала Гиббса

$$
d G^{\mathrm{s}}=d U^{\mathrm{s}} p T d S^{\mathrm{s}} .
$$

Здесь $G^{\mathrm{s}}, U^{\mathrm{s}}, S^{\mathrm{s}}$ - потенциал Гиббса, полная энергия и энтропия поверхности комплексов ВТО. Как следовало из $(2), d U^{\mathrm{s}}$ при коагуляции становится минимальной и основной вклад $d G^{\mathrm{s}}$ вносит энтропийная составляющая $d S^{\text {s }}$, т.е. выполняется условие

$$
d G^{\mathrm{s}} / d S^{\mathrm{s}}<0
$$

которое и определяет устойчивость коагулировавших наночастиц ВТО в КС. На реологию коагулировавших структур, сформировавшихся за счет доминирующей роли сил Ван-дер-Ваальса, которые состоят из наночастиц ST BTO с ДЭС, разделенных водными прослойками, сильное влияние оказывают внешние воздействия.

Очевидно, $d U^{\mathrm{s}}$ водных коагулянтов при их переносе на плоскую водную поверхность дэионизованной воды $(18 \mathrm{M} \Omega \cdot \mathrm{cm})$ в методе Ленгмюра-Блоджетт скачкообразно изменится за счет сил поверхностного натяжения. Для наиболее характерного гидродинамического диаметра коагулянта при нормальных условиях (рис. $1, b-\sim 200 \mathrm{~nm}$ ) полная энергия составит $U_{\mathrm{sp}}^{\mathrm{s}}=\sigma_{\mathrm{B}} 4 \pi R_{\mathrm{cl}}^{2}$. В момент контакта коагулянтов с плоской поверхностью воды доминирующее влияние на уменьшение полной энергии может оказать только область контакта. Так как точка контакта коагулянта становится, по крайней мере, сопоставимой с размером наночастиц ST ВТО внутри коагулянта $(\sim 20 \mathrm{~nm})$, то $U_{\mathrm{sf}}^{\mathrm{s}}=\sigma_{\mathrm{B}} 4 \pi R_{\mathrm{BTO}}^{2}$. Очевидно, что $U_{\mathrm{sf}}^{\mathrm{s}} \ll U_{\mathrm{sp}}^{\mathrm{s}}$. С учетом этого обстоятельства условие (4) может быть выполненным только за счет формирования пленочной структуры

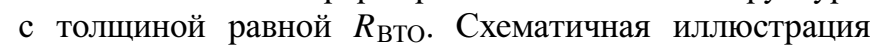
процесса формирования пленки ВТО на водной субфазе представлена на рис. 2.

Сегнетоэлектрические пленки наночастиц ST BTO осаждались на различные подложки (аморфная (стекло), монокристаллическая (кремний (100)) и поликристаллические на стекле с магнетронными пленками $\mathrm{Pt}$ и $\mathrm{Ni}-\mathrm{Cr}$, а также на подложке с серебряными наночастицами для поверхностно усиленного комбинационного рассеяния света) по ранее определенным оптимальным параметрам: объем $-3 \mu 1$, скорость движения барьеров $-5 \mathrm{~mm} / \mathrm{min}$, давление переноса $-25 \mathrm{mN} / \mathrm{m}$; температура $295 \mathrm{~K}$ [13].

Сравнение СЗМ изображений поверхностей подложек до и после нанесения ST ВТО и их гранулометрический анализ диаметров эквивалентного диска (диаметр диска 

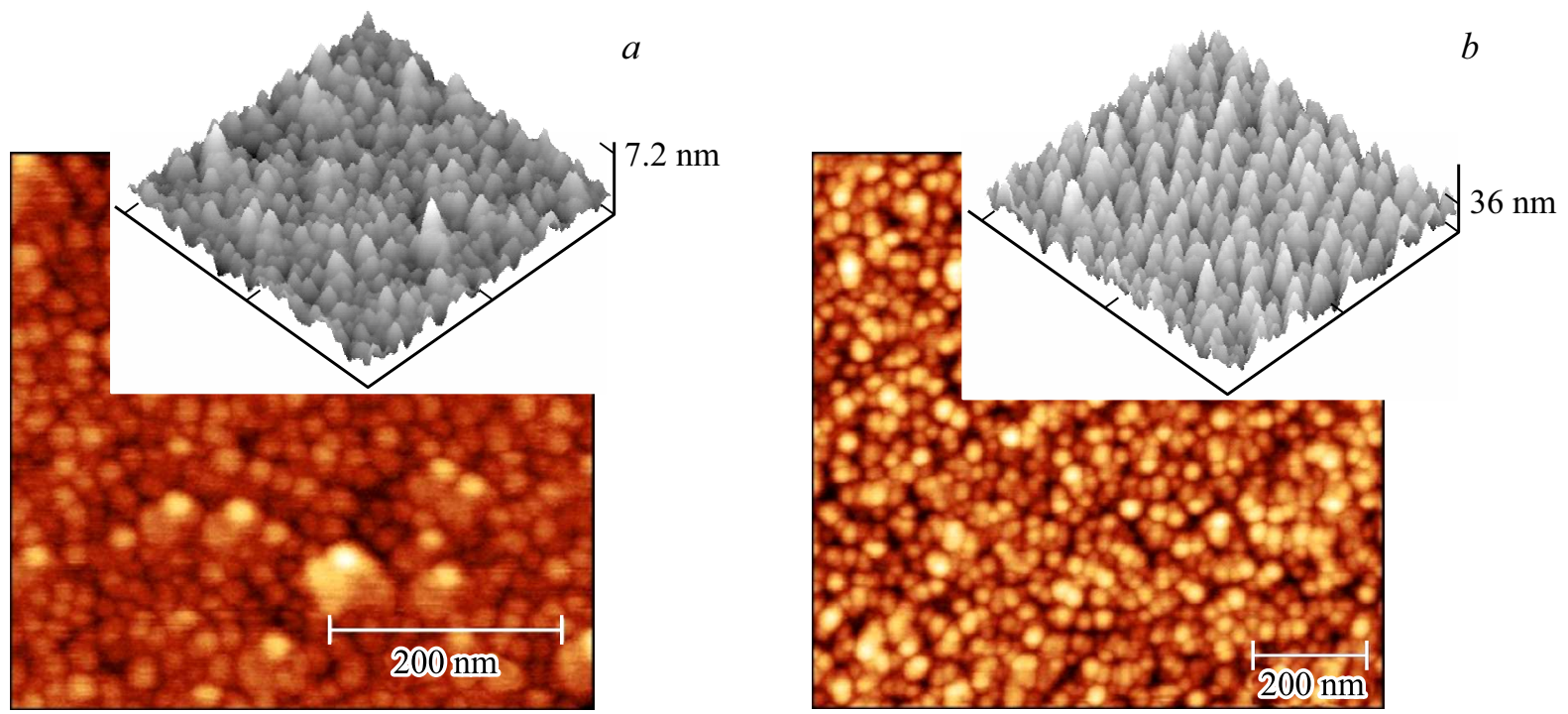

Рис. 3. C3M 3D-визуализация поверхностей SERS-подложки с указанием размеров по высоте и их 2D-изображения до осаждения пленки ST ВТО $(a)$ и после $(b)$.

$a$
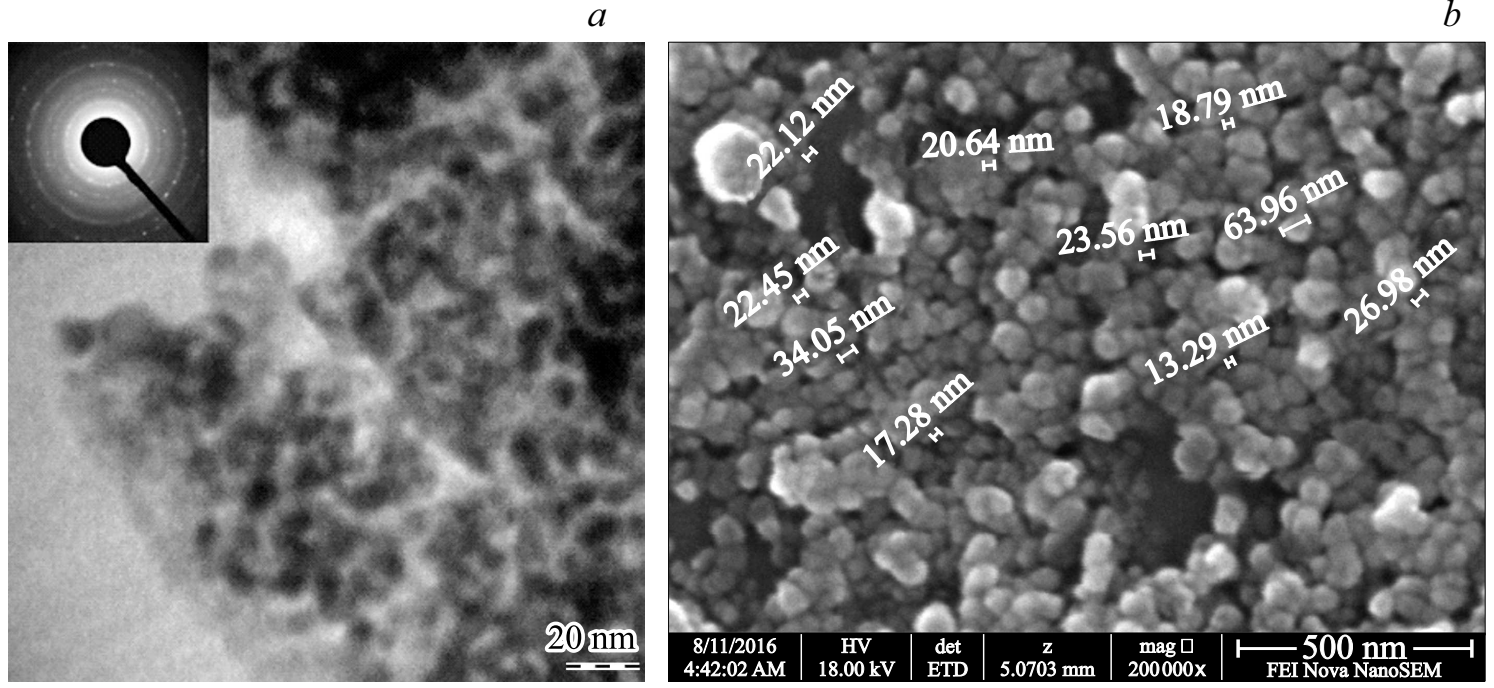

Рис. 4. ПЭМ и СЭМ изображения структуры пленки ВТО: $a-$ ПЭМ изображение с электронограмой (на вставке) кристаллической структуры пленки ВТО, $b-$ СЭМ изображение.

с той же площадью проекции, что и у зерна) и среднеквадратичные (RMS) шероховатости подложек $\left(R_{\mathrm{S}}\right)$ и пленок $\left(R_{\mathrm{LB}}\right)$ с помощью ПО Gwyddion,представленные в табл 1 , позволили установить как факт осаждения, так и отсутствия пленок на выбранные подложки.

В случае подложки с подслоем из Pt исходная коагулянтная структура магнетронного напыления оказалась полностью покрыта регулярными в виде рядов близкоразмерными наночастицами. Из сравнения структур SERS-подложки и пленки ВTO на ней (рис. 3) отмечалось возникновение диагонально направленных рядов с периодом порядка размера отдельной частицы. Из табл. 1 видно совпадение средних размеров наночастиц в пленках ST BTO при их осаждении на
Pt- и SERS-подложки, которые составили $21.6 \mathrm{~nm}$, а также различие $R_{\mathrm{S}}$ и $R_{\mathrm{LB}}$. Во всех этих случаях пленки характеризовались коэффициентом переноса $k_{\mathrm{tr}} \sim 1$.

В то же время для подложки с подслоем из Ni коагулянты явно просматривались и после нанесения пленки. Коэффициент переноса для данных пленок намного меньше единицы, $R_{\mathrm{S}} \approx R_{\mathrm{LB}}$, а размеры частиц $\mathrm{ST}$ ВТО практически оказались равными характерным размерам структур на самой подложке. Из вышеизложенного был сделан вывод о том, что наилучшее качество пленок ST BTO достигается на Pt- и SERS-подложках. Bce дальнейшие исследования выполнены с их применением.

Отметим, что СЗМ изображения структуры исходных поверхностей стекла и кремния не содержали коагулян- 
$a$
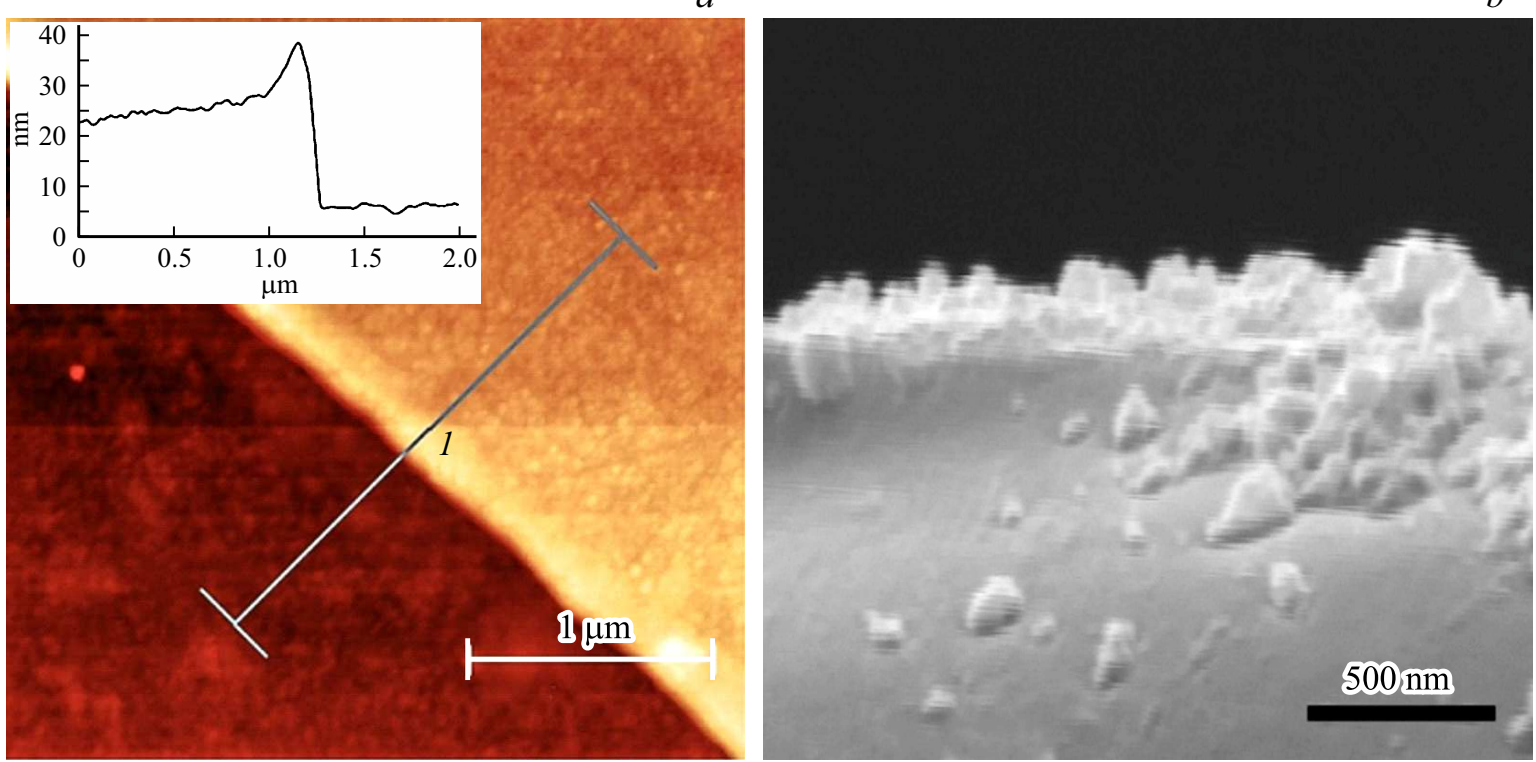

Рис. 5. СЗМ изображение пленки ВТО на платиновом подслое и профиль СЗМ изображения вдоль направления 1 (a), СЭМ изображение торца пленки ВТО $(b)$.
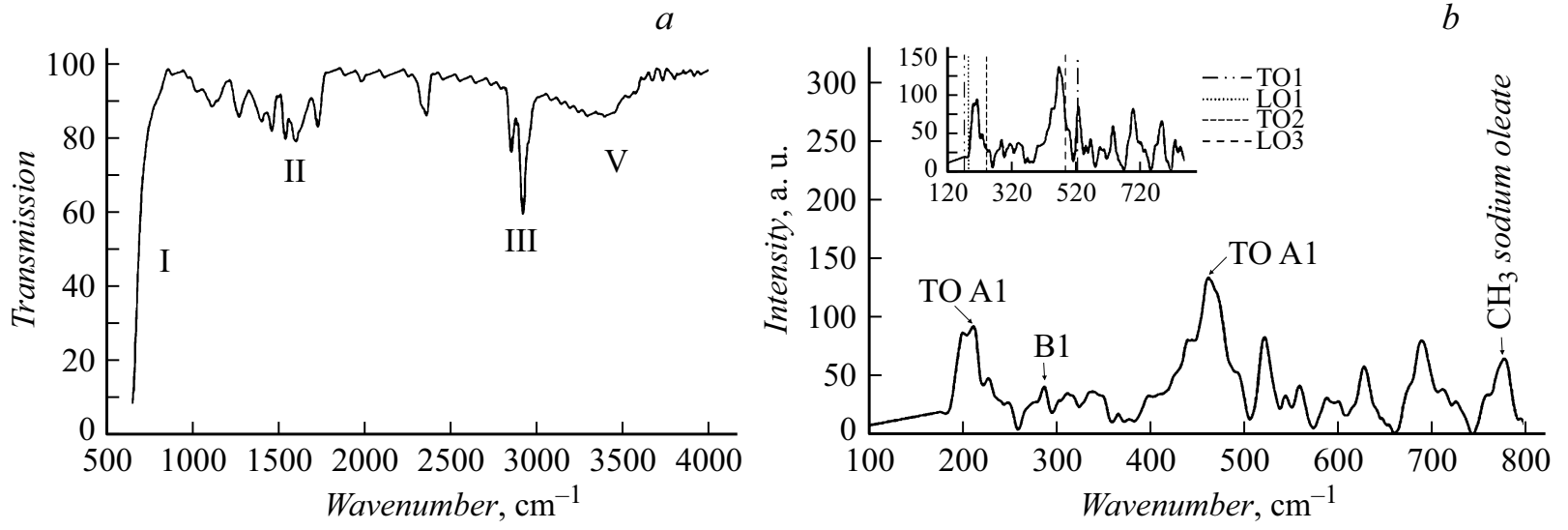

Рис. 6. $a$ - ИК-Фурье спектр ВТО, $b$ - обзорный и детальный (на вставке) спектры КРС для ЛБ пленки ВТО.

тов. Достаточно высокое значение $k_{\mathrm{tr}}=0.6-1.2$ должно было бы приводить к формированию пленки ST ВТO на стекле. Однако средние размеры и шероховатость, характеризующие как саму поверхность стекла, так и осаждаемые пленки наночастиц ВТО на ней, оказались одинаковыми. Отмечается совпадение средних размеров наночастиц в пленках BTO при их осаждении на Si-подложку и изменение RMS, характерное при осаждении пленки, однако после нанесения ВТО упорядочение наночастиц не возникло.

На рис. 4, а представлено ПЭМ изображение пленки ST BTO (1 слой с использованием типовой медной сеточки и пленки BUTVAR B-98 [18]). Здесь же на рис. 4, $b$ представлено СЭМ изображение пленки ST BTO (8 слоев) на стеклянной подложке с магнетронно-напыленным подслоем из Pt. Как видно из рис. 4 пленка представлена наночастицами со средним характерным размером око- ло $20 \mathrm{~nm}$, на фоне которых видны как более крупные коагулянтные образования, так и достаточно мелкие наночастицы (менее $14 \mathrm{~nm}$ ).

По данным ПЭМ, как показано на рис. 4, $a$, ЛБ пленки ST BTO преимущественно представлены наночастицами сферической формы размером порядка 10-20 nm. Картина дифракции электронов (вставка рис. 4, $a$ ), представляет собой концентрические дифракционные рефлексы, что прямо указывает на наличие в ЛБ пленках ST ВТО кристаллической структуры. Анализ электронограммы дает следующий ряд межплоскостных расстояний: $2.83 \AA$ (101); $2.31 \AA(111) ; 2.01 \AA$ (002); $1.64 \AA$ (112); $1.41 \AA$ (202); $1.34 \AA$ (003), отвечающих $\mathrm{BaTiO}_{3}$. Отметим, что измеренные на ПЭМ и СЭМ размеры частиц, составляющих пленку ST ВТO, согласуются с данными СЗМ (табл. 1) и МУРР [13]. 

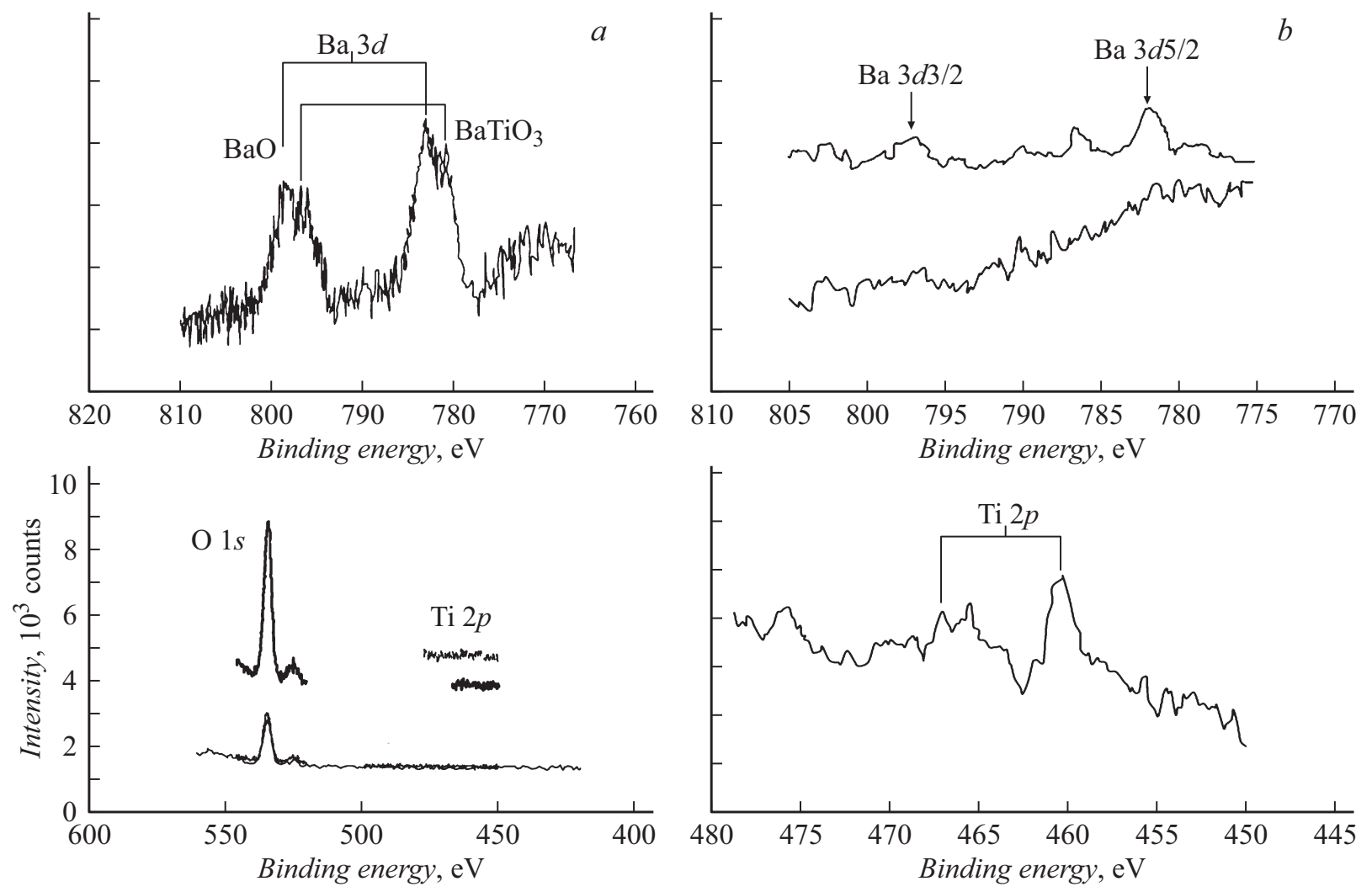

Рис. 7. $a-$ спектры РФЭС пленок, полученных методом из капли на подложке Мо в области энергии связи, $b-$ спектры РФЭС (10 проходов) ЛБ пленок ВTO из 34 слоев на SERS-подложке.
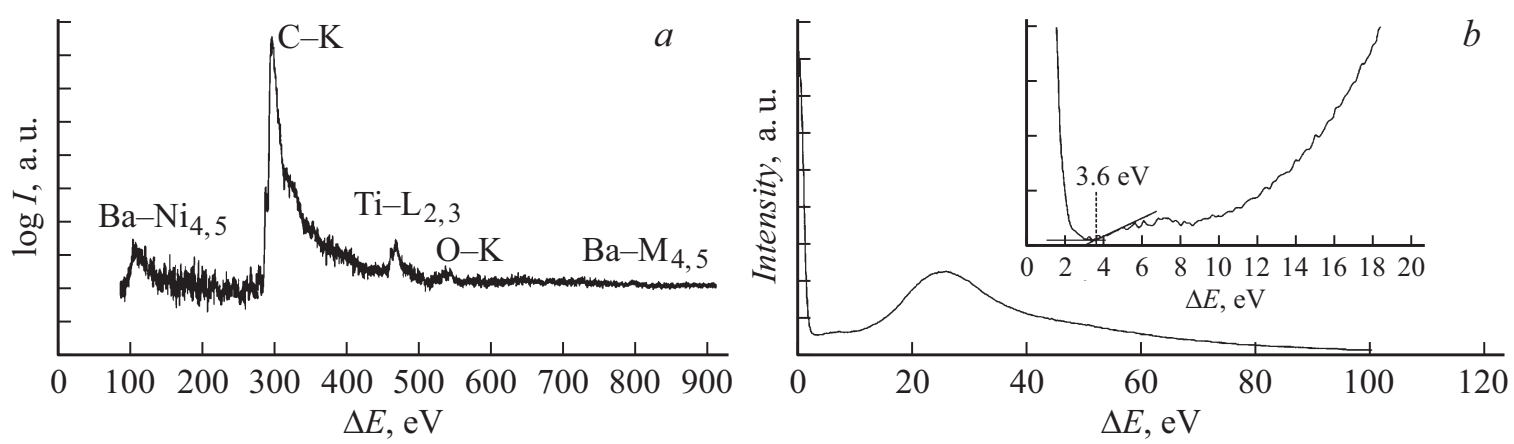

Pис. 8. $a-$ спектроскопия характеристических потерь энергии электронов ЛБ пленки ВТО, $b-$ спектры характеристических потерь энергии электронов в области с минимальными энергиями.

Для определения толщины получаемой пленки был зафиксирован ее торец на СЭМ изображении (рис. $5, b)$, а также использовался метод „ступеньки“ (рис. 5, a), который заключался в измерении разниц высот между следующими поверхностями: подложка-слой $\mathrm{Pt}$ и подложка-пленка ВТО на подслое Pt с помощью СЗМ. По Z-профилю вдоль направления 1 (рис. 5, $a$ ) толщина одного слоя пленки ВТО составила $13 \mathrm{~nm}$. Усредненная по СЭМ изображению толщина пленки из 8 слоев (рис. $5, b$ ) составила $115 \mathrm{~nm}$. Таким образом, расчетная высота одного слоя составила $14 \mathrm{~nm}$, т.е. фактически совпала с данными СЗМ микроскопии. Как следует из измерений МУРР [13], основными размерами ВТО и ЛБ пленки являются 5 и $12 \mathrm{~nm}$, так как после центрифугирования большие размеры: 27 и $37 \mathrm{~nm}$ отсутствуют (рис. 4). С учетом их долевого участия в формировании ленгмюровских пленок среднестатическая ее толщина как однослойной (рис. $5, a$ ), так и многослойной (рис. $5, b$ ), действительно составляет $\sim 14 \mathrm{~nm}$, что согласуется с выводами о расположении осаждаемых частиц на подложке по данным [19].

На рис. 6, а представлен ИК спектр ЛБ пленки ST ВТО (8 слоев). Из-за особенности синтеза наночастиц ВTO, его спектр представлен нехарактерными линиями, являющимися остатками прекурсоров, используемых при синтезе, а также их стабилизаторами в виде гид- 


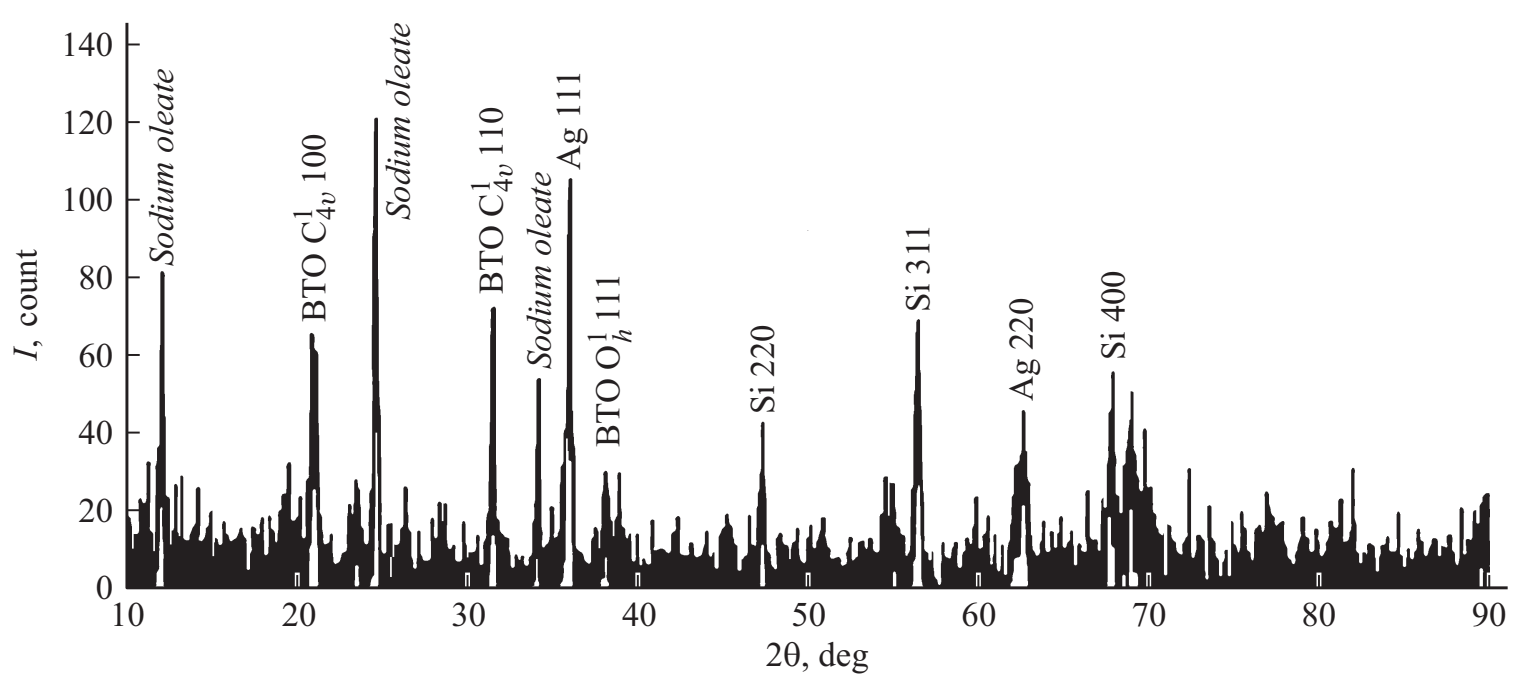

Рис. 9. Рентгеновская дифрактограмма ЛБ пленки ВТО.

роксильной группы и олеата натрия. ИК-спектр условно можно разделить на 4 области: в диапазоне волновых чисел между $530-700 \mathrm{~cm}^{-1}$ (область I) линия $650 \mathrm{~cm}^{-1}$ обусловлена колебаниями Ті-О-связи. Небольшие по интенсивности пики $1152-1734 \mathrm{~cm}^{-1}$ (область II) связаны с колебаниями карбоксилатов СОО олеата натрия. Более интенсивные линии поглощения 2857 и $2916 \mathrm{~cm}^{-1}$ (область III) обусловлены валентными колебаниями $\mathrm{CH}_{2}$ - и $\mathrm{CH}_{3}$-групп молекул олеата натрия. Область IV $\left(3200-3600 \mathrm{~cm}^{-1}\right)$ обусловлена формированием связи между СОО молекулы олеата натрия и поверхностной ОН-группой наночастиц ВТО.

Химическая структура ЛБ пленок изучена также методом комбинационного рассеяния света (КРС), применение которого для таких объектов становится возможным только при использовании SERS-подложек, усиливающих сигнал КРС до $10^{7}$ раз.

В спектре КРС наблюдались линии, соответствующие тетрагональной и кубической структурам $\mathrm{BaTiO}_{3}$. Так, в представленном на рис. $5, b$ спектре для ЛБ пленки ST BTO обнаружены линии, отвечающие за поперечные - TO1, TO2 и ТО4 и продольные - LO1, LO3 и LO4 оптические колебания, которые наблюдались и в [20,21]. В спектральной области $>700 \mathrm{~cm}^{-1}$ наблюдаются линии, принадлежащие колебаниям олеата натрия, окружающего ядро из ВТО.

Состав химической структуры ЛБ пленок ВТО был изучен методом РФЭС. По обзорным спектрам РФЭС ЛБ пленок ВТО различных толщин на SERS и магнетронной пленке $\mathrm{Pt}$ не удалось обнаружить остовные линии $2 p$ и $3 d$ атомов Ті и Ва даже с использованием алюминиевого катода, обладающего более высокой энергией. Обнаружены только возбуждения стабилизирующей оболочки из олеата натрия, включающей $\mathrm{Na} 1 s, \mathrm{O} 1 s, \mathrm{C} 1 s$. Однако в многопроходном режиме (до 10 проходов с алюминиевым катодом) на многослойных ЛБ пленках (34 и 40 слоев) установлено присутствие всех химических элементов ВТО (Тi $2 p, \mathrm{Ba} 3 d$ и $\mathrm{O} 1 s)$, а также стабилизирующей оболочки из олеата натрия.

Как видно из рис. 7, спектры в области энергий связи Ті $2 p$, Ва $3 d$ представлены дублетными линиями в отличие от спектра РФЭС для пленки ВТО, полученной методом из капли, где наблюдался дублет только для Ва $3 d$. Это изменение в спектре РФЭС может свидетельствовать о стехиометричности химического состава при формировании пленки ВТО методом ЛБ.

Для повышения интенсивности линий РФЭС остовных электронов Тi $2 p$, Ва $3 d$ было проведено ионное травление полученных ЛБ пленок ST BTO, что должно было бы удалить стабилизирующую оболочку из олеата натрия на поверхностях наночастиц ВТО. Травление образцов ЛБ пленок производилось ионами $\mathrm{N}_{2}^{+}$, генерируемыми из газовой смеси $\mathrm{Ar}^{+}, \mathrm{H}_{2}^{+}$и $\mathrm{N}_{2}^{+}$с энергией $5 \mathrm{keV}$ со скоростью $0.01 \mathrm{~nm} / \mathrm{s}$. В ЛБ пленке из 34 слоев наблюдалось уменьшение содержания натрия (на $0.2 \%$ ) и углерода (на $56.6 \%$ ), что обусловлено стравливанием олеата натрия из стабилизирующей оболочки, вследствие чего обнажается ядро титаната бария (увеличивается содержание Ті на $0.4 \%$ и в меньшей мере $\mathrm{Ba}-0.1 \%)$. Отметим, что в результате каждого двухминутного травления удалялся слой толщиной $1.2 \mathrm{~nm}$, что фактически соответствует толщине оболочки, которая составляет $2 \mathrm{~nm}$ [22]. Однако анализ данных по интенсивности относительно С $1 s$ даже после второго травления, когда удалено $2.4 \mathrm{~nm}$, показал наличие углеродного наполнения между отдельными наночастицами ST ВTO в ЛБ пленке. Величина интенсивности воздействия ионов $\mathrm{N}_{2}^{+}$обеспечивала удаление только оболочки, не затрагивая ядро, что подтверждается неизменностью содержания $\mathrm{Ti} 2 p, \mathrm{Ba} 3 d$, даже после второго травления. В пользу этого свидетельствуют данные по травлению в течение $3 \mathrm{~min}$ двуслойной ЛБ пленки, когда уменьшилось содержание $\mathrm{Na} 1 s, \mathrm{O} 1 s, \mathrm{C} 1 s$ при некотором увеличении интенсивности Ті $2 p$, что, видимо, 
Таблица 2. Параметры кристаллических решеток ВТО

\begin{tabular}{|c|c|c|c|c|c|}
\hline \multirow{2}{*}{$\begin{array}{l}\text { Структура } \\
\text { решетки }\end{array}$} & \multicolumn{2}{|c|}{$\begin{array}{c}\text { Параметр решетки } \\
\text { в пленках ВТО, А }\end{array}$} & \multirow{2}{*}{$\begin{array}{c}\text { Параметры решетки } \\
\text { в объемных образцах, } \AA\end{array}$} & \multicolumn{2}{|c|}{ Различие,\% } \\
\hline & BTO / Ag & $\mathrm{BTO} / \mathrm{Pt}[24]$ & & $\mathrm{BTO} / \mathrm{Ag}$ & $\mathrm{BTO} / \mathrm{Pt}$ \\
\hline Кубическая & $a=3.973$ & $a=3.992$ & $a=4.009$ & $0.9 \%$ & $0.4 \%$ \\
\hline Тетрагональная & $\begin{array}{l}a=4.005 \\
c=4.035\end{array}$ & $\begin{array}{l}a=3.937 \\
c=4.25\end{array}$ & $\begin{array}{l}a=3.992 \\
c=4.036\end{array}$ & $\begin{array}{l}0.3 \% \\
0.02 \%\end{array}$ & $\begin{array}{l}1.3 \% \\
2.7 \%\end{array}$ \\
\hline
\end{tabular}

вызвано подтравливанием уже ядра наночастиц ST BTO. Некоторым диссонансом представляются данные по О $1 s$ и $\mathrm{Ag} 3 d 5 / 2$, которые могут объясняться возможным окислением серебра, так как при травлении имеет место разогрев области обработки в среде богатой кислородом.

В соответствии с результатами исследований элементного состава ЛБ пленки ST ВTO по данным спектроскопии характеристических потерь энергии электронов в диапазоне от $70 \mathrm{eV}$ (рис. 8, a) было установлено наличие линий, соответствующих: углероду $\mathrm{C}-K$, в полимерной пленке BUTVAR B-98 и стабилизирующей оболочке на наночастицах, титану - Ti- $L_{2,3}$, кислороду - O- $K$ и барию - Ba- $N_{4,5}, M_{4,5}$, а также $\mathrm{Na}-L_{2,3}$ в области низких энергий $(<70 \mathrm{eV})$.

Для определения ширины запрещенной зоны $\left(E_{g}\right)$ для ЛБ пленки ВТО по спектру характеристических потерь энергии электронов были проведены исследования в диапазоне минимальных энергий (рис. 8, b). Полученная методом стандартной экстраполяции зависимости потерь энергии электронов ширина запрещенной зоны для изучаемых пленок ВТО составила $3.6 \mathrm{eV}$, что согласуется с данными [23].

Особенности кристаллической структуры и фазового состава ЛБ пленок BTO на SERS-подложках (24 слоя) были изучены методом рентгеновской дифракции. Интенсивность рефлексов дифракционных максимумов на полученной рентгенограмме позволила определить как параметры кристаллической решетки, так и ее сингонию (рис. 9). При комнатной температуре обнаружены рефлексы тетрагональной (сегнетоэлектрической) $\left(C_{v}^{1}\right)$ фазы, а также метастабильной кубической фазы $\left(O_{h}^{1}\right)$, как остаточной после пероксидного синтеза [12]. Результаты рентгенофазового анализа согласуются с представленными выше данными электронографического анализа (рис. 7, a). Следует отметить, что интенсивность рефлексов, наблюдаемых в пленке ST ВTO, мала, что не позволяет наблюдать линии на углах $2 \theta>\pi / 2$.

Для ЛБ пленок ST BTO на SERS-подложках с подслоем из Ag с помощью ПО PowderCell были проведены расчеты параметров решетки. Результаты представлены в табл. 2. Здесь же для сравнения приведены эти параметры для пленок ВТО /Pt, полученных методом лазерной абляции [24], а также их известные значения для объемных образцов. Из сравнения данных параметров решетки с их значениями для пленок можно отметить хорошее согласие с данными, полученными методом электронной дифракции (вставка рис. 7, a) и [25].

Согласно табл. 2, коэффициент тетрагональности $(k=c / a)$ у сегнетоэлектрической пленки ВТО на серебряном и платиновом подслоях существенно отличаются: $k_{\mathrm{Ag}}=1.007, k_{\mathrm{Pt}}=1.054$. При этом $k_{\mathrm{Ag}}$ также как и параметры решетки оказывается наиболее близкими с их значениями для объемного ВТО, для которого $k=c / a \sim 1.01$. Если судить по коэффициенту тетрагональности $k$ наибольшее усиление сегнетоэлектрических свойств ВТО, одним из проявлений которых является поляризация, достигается на пленках с платиновым подслоем [26].

\section{Выводы}

Исследована коллоидная система стабилизированных олеатом натрия наночастиц титаната бария, полученных методом пероксидного синтеза, которые имеют сферическую форму с диаметрами 10, 24, 54 и $74 \mathrm{~nm}$, из которых за счет коагуляционного механизма формируются сферические коагулянты с наиболее характерным гидродинамическим диаметром $\sim 200 \mathrm{~nm}$.

Установлено, что при осаждении методом ЛенгмюраБлоджетт стабилизированных наночастиц ВТО на различные подложки наиболее качественные пленки формируются на подслоях Ag и Pt с образованием регулярных плотноупакованных структур из этих частиц, разделенных оболочкой толщиной $2.4 \mathrm{~nm}$ из олеата натрия, по атомно-силовым и электронно-микроскопическим измерениям толщина легмюровских пленок $\sim 14 \mathrm{~nm}$. Ширина запрещенной зоны полученных пленок составила $3.6 \mathrm{eV}$.

Сегнетоэлектрические пленки титаната бария, полученные методом Ленгмюра-Блоджетт, характеризуются высокой сплошностью и однородностью по структуре и составу, что делает их перспективным материалом для микро- и наноэлектронике.

\section{Финансирование работы}

Исследования выполнены при поддержке Министерства образования и науки РФ в рамках Госзадания № $16.2814 .2017 / П Ч$. 


\section{Конфликт интересов}

Авторы заявляют, что у них нет конфликта интересов.

\section{Список литературы}

[1] Paniagua S.A., Kim Y., Henry K. // Appl. Mater. Interfaces. 2014. Vol. 6. P. 3477-3482.

[2] Cole M.W., Weiss C.V., Ngo E., Hirsch S., Coryell L.A. // Appl. Phys. Lett. 2008. Vol. 92. P. 182906-1-182906-3.

[3] Jain Raj Kumar, Dubey Ashish, Soni Amit, Gupta Sanjiv Kumar, Shami Trilok Chand // Process. Applic. Ceram. 2013. Vol. 7. P. 189-193.

[4] Bo Lin Cheng, Maurice Gabbay, Mario Maglione, Gilbert Fantozzi // J. Electroceramics. 2003. Vol. 10. P. 5-18.

[5] Tetsuro Tohma, Hiroshi Masumoto, Takishi Goto // Mater. Transactions. 2002. Vol. 43. P. 2880-2884.

[6] Vijay Ramkrishna Chinchamalatpure, Sharada Arvinda Ghosh, Gajanan Niranjanrao Chaudhari // Mater. Sci. Appl. 2010. Vol. 1. P. 187-190.

[7] Stoica L., Bygrave F., Bell A.J. // U.P.B. Sci. Bull. Series A. 2013. Vol. 75. P. 147-58.

[8] Kumbhar S.S., Mahadik M.A., Chougule P.K., Mohite V.S., Hunge Y.M., Rajpure K.Y., Moholkar A.V., Bhosale C.H. // Mater. Sci. Poland. 2015. Vol. 33. P. 852-861.

[9] John P. George, Jeroen Beeckman, Wouter Woestenborghs, Philippe F. Smet, Wim Bogaerts, Kristiaan Neyts // Nanoscale Research Lett. 2013. Vol. 62. P. 1-7.

[10] Pfaff G., Feltz A. // Cryst. Res. Technol. 1990. Vol. 25. P. $1039-1047$.

[11] Kuzmenko A., Sizov A., Yacovlev O., Emelianov N. // J. Nanoand Electron. Phys. 2013. Vol. 5. P. 04024-1-04024-2.

[12] Emelianov N.A. // Europ. Phys. J. Appl. Phys. 2015. Vol. 69. P. 10401-10406.

[13] Kuzmenko A.P., Chuhaeva I.V., Abakumov P.V., Dobromyslov M.B., Emelyanov N.A. // J. Nano- and Electron. Phys. 2015. Vol. 7. 04025-1-04025-4.

[14] Serra-Gómez R., Dreiss C.A., González-Benito J., González-Gaitano G. // Langmuir. 2016. Vol. 32. P. 63986408.

[15] Songhak Yoon, Sunggi Baik, Min Gyu Kim, Namsoo Shin, Insung Kim // J. Korean Ceram. Society. 2006. Vol. 43. P. 710-714.

[16] Wei Wang, Baohua Gu, Liyuan Liang // J. Dispers. Sci. Technol. 2004. Vol. 25. P. 593-601.

[17] Derjaguin B.V. Theory of Stability of Colloids and Thin Films. Springer, 1989. 258 p.

[18] Pugachevskii M.A., Karpovich N.F. // J. Appl. Spectroscopy. 2015. Vol. 82. P. 673-676.

[19] Adam Detrich, Andras Deak, Erzsebet Hild, Attila L. Kovacs, Zoltan Horvolgyi // Langmuir. 2010. Vol. 26. P. 2694-2699.

[20] Hayashi H., Nakamura T., Ebina T. // J. Phys. Chem. Sol. 2013. Vol. 74. P. 957-962.

[21] Lazarevic Z., Romčevic N., Vijatović M., Paunovic N., Romcevic M., Stojanovic B., Dohcevic-Mitrovic Z. // Acta Phys. Polonica A. 2009. Vol. 115. P. 808-810.

[22] Shinn-Jen Chang, Wei-Sheng Liao, Ci-Jin Ciou, Jyh-Tsung Lee, Chia-Chen Li // J. Colloid Interface Sci. 2009. Vol. 329. P. 300-305.

[23] Mohammed Q.A., Ali Z.R., Mijbas A.F. // J. Babylon University (Eng. Sci.). 2012. Vol. 20. P. 12-16.
[24] Minnekaev M., Bulakh K., Chouprik A., Drube W., Ershov P., Lebedinskii Yu., Maksimova K., Zenkevich K. // Microelectron. Eng. 2013. Vol. 109. P. 227-231.

[25] Paula Ferreira, $R u$ Z. Hou, Aiying Wu, Marc-Georg Willinger, Paula M. Vilarinho, Jadra Mosa, Christel Laberty-Robert, Cedric Boissiere, David Grosso, Clément Sanchez // Langmuir. 2012. Vol. 28. P. 2944-2949.

[26] Kuzmenko A.P., Chuhaeva I.V., Abakumov P.V., Dobromyslov M.B. // J. Nano- and Electron. Phys. 2016. Vol. 8. P. 04043-1-04043-2. 